\title{
Dual Attributes of Government Intervention and China's Real Estate Prices-Is Chinese Government a Promoter of the Real Estate Prices?
}

\author{
Hong $\mathrm{Xu}^{1}$, Hui Wang ${ }^{1}$, Chunming Zhou ${ }^{1} \&$ Zhen Geng ${ }^{1}$ \\ ${ }^{1}$ School of Business, Shandong Normal University, Jinan, 250014, China \\ Correspondence: Hui Wang, School of Business, Shandong Normal University, No. 88 East Wenhua Road, Jinan City, \\ China. Tel: 86-158-6314-7504.
}

Received: May 21, 2016

Accepted: June 11, 2016

Online Published: June 21, 2016

doi:10.5430/afr.v5n3p29

URL: http://dx.doi.org/10.5430/afr.v5n3p29

Funds: Natural Foundation research project from Shandong Province (ZR2012GQ001)

Graduate Research Fund from Shandong Normal University (SCX201636)

\begin{abstract}
Real estate prices is the most controversial topic of people's livelihood, based on the dual attributes of government intervention,this article analyzes equilibrium properties of real estate prices and government intervention on real estate prices with two-tier stochastic frontier model. The results show that government intervention does play a leading role in the promotion process of real estate prices. Chinese buyers were forced to accept a higher prices than the equilibrium prices, but the net surplus that the government seized from the real estate has been decreasing year by year, the government is intended to make the real estate prices stable through policy intervention; Besides, the degree of intervention shows a significant geographical feature, that is, the eastern region's intervention is the strongest, followed by the western and the central.
\end{abstract}

Keywords: Real estate prices, Government intervention, Two-tier stochastic frontier model, Equilibrium prices

\section{Introduction}

Since the 21 st century, the real estate industry step into the "golden decade". It has made a significant contribution on the development of the national economy. But at the same time, the gap between the real estate prices growth and people's income has enlarged, and so many buyers feel powerless and frustrated. Excessive high real estate prices makes the real estate rigid demanders put most of their income in housing savings, which resulting in the insufficient of investment and consumption, the loss of social welfare, the decrease of people's satisfaction. Therefore the stable development of the real estate prices has become an important issue on the national economy and people's livelihood. How to curb the rapid rise of real estate prices and make it return to a rational growth level has become the focus. In face of increasing people's welfare and economics, the government's price intervention policy is often in dilemma. Whether the blame to national government - "land sales to get money" is true, What is the impact of government intervention on prices? Is the intention of the government intervention to stabilize housing prices or to promote the economy? This article will discuss the above issues.

This paper argues that the impact of the government intervention on prices has dual attributes. On the one hand, the government has the tendency to control the real estate price's growth proceed from stabilizing people's livelihood and improving people's satisfaction; On the other hand, the real estate industry plays an important role in the development of Chinese economy, so the government has the tendency to keeping the real estate prices increasing. This paper use the two-tier stochastic frontier model to analyze the influence of government intervention on the real estate prices from the perspective of intervention effect, periodic characteristics and the differences of regional. In this paper, we provide a powerful evidence about the impact on real estate prices changes from Chinese government intervention policy.

\section{Literature Review}

The majority of Chinese local governments made about $60 \%$ of its revenue from land resource-related taxes and land-transferring fees during 2000-2009.And the land finance is the main source of local governments' fiscal revenue. In addition, the strengthen of the fiscal decentralization level, the competitive effects among local governments and 
the GDP growth which constitutes the performance evaluation system are important factors leading to the real estate prices rising. Harris et al (2001) have shown that the influence of the federal government's spending and local governments' spending on housing prices are different, and the local government's spending can improve prices significantly; According to $\mathrm{Li}$ and $\mathrm{Li}$ (2012),fiscal decentralization and local government competition have a significantly positive effect on housing prices. We need establish a sound financial regulatory system and increase the proportion of the local government in the fiscal revenue to make home prices rational growth; Besides that, Paulo (2002) establishes an endogenous growth model to prove that a region's economic growth rate is affected by the relative prices of housing and other capital on the assumption that the housing and other assets can be not completely replaced; $\mathrm{Du}(2011)$ finds that the land price is the Granger reason of home prices by Granger causality test, not vice versa; In addition, Lu (2011) show that China's fiscal decentralization can promote the behavior of the government land leasing and narrow the gap in per capita local financial resources; Guo (2013) points out that the shortfall of local government revenue has a significantly positive impact on housing prices and the behavior of local government intervention play a key role in the house prices rising; Fan and $\mathrm{Wu}$ (2013) have analyzed the capitalization of public expenditure in the housing prices and land price, they think that the capitalization of public expenditure in the housing prices is weaker than that of the land price. So the local government get more capital gains. The behavior of local government is a reflection of local government officials behavior. Perfect performance is the guarantee of official promotion. Qian (2011) and Zhu (2013) are agreed with them.

The rapid growth of real estate prices is also an important factor causing the loss of social welfare and rich-poor polarization. Kim \& Ju (2003) find that the housing supply can significantly promote economic growth , but also lead to a deterioration of income distribution and a decline of overall welfare; According to Chen and Qiu (2011),high housing prices make urban residents feel inequality and the Low-income groups feel more; Li (2005) and Liang (2010) document that the inequality of the real estate and financial assets directly determines the inequality of the total property. $60 \%$ of these inequality is determined by real estate. At the same time, Yu and Lin (2010) explore the decision mechanism of basic housing prices and the results show that: the income of consumer, the cost of construction, the scale of the loan and the market forces of developer are all driving factors of housing prices rising. $60 \%$ of rising can be explained by government intervention. And the government support take a proportion of $60 \%$; Yuan (2012) shows that whether rise or fall of housing prices all make the real income of residents fall, but the impact on low-income groups is more serious; Chen and Fan (2014) carry out the study on inflation by using the impulse response function and Bayesian decomposition, and the results show that loose monetary policy play a major role on promoting China's housing prices. At the same time, he points out that increasing real estate supply and curbing the prices of house can reduce the loss of social welfare. Based on the above discussion, in consideration of increasing the social welfare and narrowing the wealth gap, the government must take appropriate measures to stabilize real estate prices. Based on housing stock model, Wang (2011) makes a quantitative evaluation about the effect of the main intervention policy on the housing market, and finds that the national policy tools had a significant effect on the housing prices. Especially in 2005 and 2006, the state council restrained price growth through two comprehensive interventions in different forms. Shao (2012) have found that in the long-term, breaking the monopoly of urban land market contribute to curb the excessive growth of house prices. In the short term, the local government need to change the practice of maximizing land revenue as the main decision. Moreover, Chamon \& Prasad (2010) and Song \& Yang (2010) find that the saving rate of China's non-housing family is significantly higher than the family with houses, and the saving rate of young family is higher. Buying a house has become an important reason for young people to increase their savings. As the main force of China's consumption, the high saving rate of the younger generation will lead to a serious shortage of Chinese consumption and investment. In view of reducing the saving rate to increase the consumption and investment, the Chinese government has the tendency to stabilize prices.

\section{Research Design}

\subsection{A Two-Tier Stochastic Frontier Model}

Government intervention has a significant influence on the real estate prices. But considering the dual effect of the government intervention, the purpose of the intervention is quite different. When the high housing prices lead to a heavy burden on the house buyers, in view of stabilizing people's livelihood and improving the social welfare, the government has tendency to introduce corresponding policy to control the real estate prices. For example, in 2005 and 2006, a series of real estate regulations was introduced to restrain the rising of real estate prices. The real estate industry is a pillar industry of the national economy and plays an important role in the development of Chinese economy. When the growth of economy is decreased, the central government has the tendency to promote the rise of real estate prices. The same situation also applies to local government. The intervention policy exists two kinds of 
effects, the final level of real estate prices depends on the net effect. Therefore we can use the method of two-tier stochastic frontier to build a regression model (Kumbhakar and Parmeter 2009), which is set up as follows:

$$
F J S P_{i t}=F J S P_{i t}^{*}+\varepsilon_{i t}=v_{i t}-u_{i t}+w_{i t}
$$

Where $F J S P_{i t}$ is the actual level of real estate prices, $F J S P_{i t}^{*}$ is the optimal real estate prices level determined by macroeconomic factors, disturbance term $w_{i}$ and $u_{i}$ reflects the two different tendencies of the government intervention, which are positive unilateral distribution. $w_{i}$ reflects the degree that the government adopt a series of policies to promote the real estate prices. $u_{i}$ reflects the level that the government take measures to reduce the real estate prices. In order to estimate parameter $\beta$ and dual effects on real estate prices from government intervention. In this paper, we assume: (1) $v_{i} \sim$ iid. $N\left(0, \sigma_{v}^{2}\right)$, (2) $u_{i} \sim i i d . \operatorname{Exp}\left(\sigma_{u}, \sigma_{u}^{2}\right),(3) w_{i} \sim i i d . \operatorname{Exp}\left(\sigma_{w}, \sigma_{w}^{2}\right)$.

$v_{i}, w_{i}$ and $u_{i}$ are distributed independently of each other and from the regressors, $\mathrm{x}$. Based on the above assumption, probability density function can be deduced as follows:

$$
f\left(\varepsilon_{i}\right)=\frac{\exp \left(a_{i}\right)}{\sigma_{u}+\sigma_{w}} \Phi\left(c_{i}\right)+\frac{\exp \left(b_{i}\right)}{\sigma_{u}+\sigma_{w}} \int_{h_{i}}^{\infty} \varphi(z) d z=\frac{\exp \left(a_{i}\right)}{\sigma_{u}+\sigma_{w}} \Phi\left(c_{i}\right)+\frac{\exp \left(b_{i}\right)}{\sigma_{u}+\sigma_{w}} \varphi\left(h_{i}\right)
$$

Where $\varphi(\cdot)$ and $\Phi(\cdot)$ are the probability density function and the cumulative distribution function of standard normal distribution respectively, other parameters were set as follows:

$$
a_{i}=\frac{\sigma_{v}^{2}}{2 \sigma_{u}^{2}}+\frac{\varepsilon_{i}}{\sigma_{u}} ; b_{i}=\frac{\sigma_{v}^{2}}{2 \sigma_{w}^{2}}-\frac{\varepsilon_{i}}{\sigma_{w}} ; h_{i}=\frac{\varepsilon_{i}}{\sigma_{v}}-\frac{\sigma_{v}}{\sigma_{w}} ; c_{i}=-\frac{\varepsilon_{i}}{\sigma_{v}}-\frac{\sigma_{v}}{\sigma_{u}}
$$

For a sample containing $\mathrm{n}$ observations, the log-likelihood function can be expressed as follows:

$$
\ln L(X ; \theta)=-n \ln \left(\sigma_{u}+\sigma_{w}\right)+\sum_{\mathrm{i}=1}^{\mathrm{n}} \ln \left[e^{a_{i}} \Phi\left(c_{i}\right)+e^{b_{i}} \Phi\left(h_{i}\right)\right]
$$

Where $\theta=\left[\beta, \sigma_{v}, \sigma_{u}, \sigma_{w}\right]^{\prime}$. The ML estimates of all the parameters can be obtained by maximizing the above log likelihood function.

We focuses more on the net surplus of the double effect impact of government intervention in this paper, so we need to deduce the conditional distribution of $u_{i}$ and $w_{i}$, which can be represented as $f\left(u_{i} \mid \varepsilon_{i}\right)$ and $f\left(w_{i} \mid \varepsilon_{i}\right)$ respectively.

$$
\begin{aligned}
f\left(u_{i} \mid \varepsilon_{i}\right) & =\frac{\lambda \exp \left(-\lambda u_{i}\right) \Phi\left(u_{i} / \sigma_{v}+h_{i}\right)}{\Phi\left(h_{i}\right)+\exp \left(a_{i}-b_{i}\right) \Phi\left(c_{i}\right)} \\
f\left(w_{i} \mid \varepsilon_{i}\right) & =\frac{\lambda \exp \left(-\lambda w_{i}\right) \Phi\left(w_{i} / \sigma_{v}+c_{i}\right)}{\exp \left(b_{i}-a_{i}\right)\left[\Phi\left(h_{i}\right)+\exp \left(a_{i}-b_{i}\right) \Phi\left(c_{i}\right)\right]}
\end{aligned}
$$

$\lambda=1 / \sigma_{u}+1 / \sigma_{w}$ in them. With these conditional distributions in (3a) and (3b), we can derive the conditional expectation as:

$$
\begin{aligned}
& E\left(1-e^{-u_{i}} \mid \varepsilon_{i}\right)=1-\frac{\lambda}{1+\lambda} \frac{\left[\Phi\left(h_{i}\right)+\exp \left(a_{i}-b_{i}\right) \exp \left(\sigma_{v}^{2} / 2-\sigma_{v} c_{i}\right) \Phi\left(c_{i}-\sigma_{v}\right)\right]}{\Phi\left(h_{i}\right)+\exp \left(a_{i}-b_{i}\right) \Phi\left(c_{i}\right)} \\
& E\left(1-e^{-w_{i}} \mid \varepsilon_{i}\right)=1-\frac{\lambda}{1+\lambda} \frac{\left[\Phi\left(c_{i}\right)+\exp \left(b_{i}-a_{i}\right) \exp \left(\sigma_{v}^{2} / 2-\sigma_{v} h_{i}\right) \Phi\left(h_{i}-\sigma_{v}\right)\right]}{\exp \left(b_{i}-a_{i}\right)\left[\Phi\left(h_{i}\right)+\exp \left(a_{i}-b_{i}\right) \Phi\left(c_{i}\right)\right]}
\end{aligned}
$$

Furthermore, the net surplus (NS) can be expressed as:

$$
N S=E\left(1-e^{-w_{i}} \mid \varepsilon_{i}\right)-E\left(1-e^{-u_{i}} \mid \varepsilon_{i}\right)=E\left(e^{-u_{i}}-e^{-w_{i}} \mid \varepsilon_{i}\right)
$$

When do the empirical research using (1), $\sigma_{u}$ appears only in $a_{i}$ and $c_{i}$, while $\sigma_{w}$ appears only in $b_{i}$ and $d_{i}$. The policy factors that affect the real estate prices are very complex, not only including direct intervention but also indirect intervention, the advantage of two-tier stochastic frontier model compared with other regression models is that the analyst does not need to make a priori assumptions about the form of policy objectives and macro-economic factors which influence real estate prices, but to evaluate the effect of government intervention in real estate prices according to the estimation results.

\subsection{Data and Variable}

The data comes from the CSMAR database, consisting of the macroeconomic indicators of 31 provinces and municipalities during2008-2013.The level of home prices (FJSP) is measured by the log real estate prices. The income gap between urban and rural areas (CXSRC) is defined as the log per capita annual income difference between urban and rural. The growth rates of GDP are adopted to replace the level of economic development (GZ). The ratio of non-state investment and the total investment replaces the degree of market (SCH). The exports of local divided GDP (DWKF) and the log real estate completed area(JGMJ) are also introduced in the model. All results are processed by STATA11.2. The variable descriptive statistics is as follows table 1 . 
Table 1. Variable descriptive statistics

$\begin{array}{llllllll}\text { Variable } & \text { Mean } & \text { Std } & \text { Max } & \text { Min } & \text { E-mean } & \text { C-mean } & \text { W-mean } \\ \text { FJSP } & 8.4178 & 0.4736 & 9.8284 & 7.5795 & 8.8605 & 8.1852 & 8.1672 \\ \text { CXSRC } & 2.9795 & 0.5461 & 4.2809 & 2.0341 & 2.5779 & 2.7496 & 3.5009 \\ \text { GZ } & 0.1563 & 0.0626 & 0.3227 & 0.0059 & 0.1399 & 0.1561 & 0.1714 \\ \text { SCH } & 0.6823 & 0.1195 & 0.8855 & 0.2663 & 0.7581 & 0.7200 & 0.5878 \\ \text { SCHsq } & 0.4798 & 0.1513 & 0.7841 & 0.0709 & 0.5803 & 0.5253 & 0.3574 \\ \text { DWKF } & 0.1545 & 0.2430 & 1.2130 & 0.0016 & 0.3496 & 0.0642 & 0.0359 \\ \text { RJSR } & 9.3089 & 0.3535 & 10.2858 & 8.6063 & 9.6068 & 9.2286 & 9.0894 \\ \text { JGMJ } & 10.7407 & 1.3819 & 13.4288 & 5.3995 & 11.3582 & 11.1126 & 9.9267\end{array}$

\section{Empirical Results}

The main objective of estimating a two-tier stochastic frontier function is to obtain observation-specific estimates of extracted surplus by the dual influence of government policy interventions. In order to ensure the robustness of the regression results, we use different models to estimate results respectively, which is shown in table 2: Model 1 presents results by the standard OLS regression, the model II and III is maximum likelihood estimation (MLE) based on the two-tier stochastic frontier model. In the model II, we assume that the government does not have the tendency to intervene the real estate prices. In the model III, the form of random disturbance term is bilateral.

Table 2. The estimates of dual intervention

\begin{tabular}{|c|c|c|c|}
\hline \multirow[t]{2}{*}{ Dependent variable } & \multicolumn{3}{|l|}{ FJSP } \\
\hline & model I & model II & model III \\
\hline \multirow[t]{2}{*}{ CXSRC } & 0.0349 & $0.0546^{* * *}$ & $0.0631 * *$ \\
\hline & $(0.0413)$ & $(0.0014)$ & $(0.0301)$ \\
\hline \multirow[t]{2}{*}{ GZ } & 0.3724 & $0.2948 * * *$ & $0.3448^{*}$ \\
\hline & $(0.2562)$ & $(0.0289)$ & $(0.2043)$ \\
\hline \multirow[t]{2}{*}{$\mathrm{SCH}$} & $4.4408 * * *$ & $2.7208 * * *$ & $2.6077 * * *$ \\
\hline & $(0.9110)$ & $(0.0610)$ & $(0.7051)$ \\
\hline \multirow[t]{2}{*}{ SCHsq } & $-3.5330 * * *$ & $-2.6236 * * *$ & $-2.4358 * * *$ \\
\hline & $(0.7012)$ & $(0.0457)$ & $(0.5334)$ \\
\hline \multirow[t]{2}{*}{ DWKF } & $0.1952 * *$ & $0.1523^{* * *}$ & $0.2192 * * *$ \\
\hline & $(0.0756)$ & $(0.0058)$ & $(0.0592)$ \\
\hline \multirow[t]{2}{*}{ RJSR } & $1.3639 * * *$ & $1.2836^{* * *}$ & $1.2377 * * *$ \\
\hline & $(0.0671)$ & $(0.0043)$ & $(0.0624)$ \\
\hline \multirow[t]{2}{*}{ JGMJ } & $-0.0827 * * *$ & $-0.0051 * * *$ & -0.0169 \\
\hline & $(0.0175)$ & $(0.0013)$ & $(0.0160)$ \\
\hline \multirow[t]{2}{*}{$\mathrm{CON}$} & $-4.9185 * * *$ & $-4.3338 * * *$ & $-3.9290 * * *$ \\
\hline & $(0.7383)$ & $(0.0390)$ & $(0.6455)$ \\
\hline $\operatorname{Adj}-R^{2}$ & 0.8254 & & \\
\hline Log-likelihood values & & -154.9024 & 58.5101 \\
\hline LR Value (P Value) & & & $778.25(0.000)$ \\
\hline
\end{tabular}

$* * *, * *$ and $*$ represent significance at $1 \%, 5 \%$ and $10 \%$ level respectively, with the standard error in parentheses.LR is the likelihood ratio test results; The original hypothesis is "There is no difference between the two sides stochastic frontier model and the maximum likelihood estimation model".

The likelihood ratio test results show that there are significant differences between model II and III, so it is 
reasonable to assumes that the form of random disturbance term is bilateral. The following analysis are based on the estimated results of the model III .

Seen from the estimated result, urban-rural income gap(CXSRC),economic development (GZ), the level of opening to the outside(DWKF), the per capita income (RJSR)have significant positive effects on the real estate prices. Market supply(JGMJ)has negative effects on the real estate prices. The level of marketization and the real estate prices show a "inverted U-shaped" relationship. This is consistent with the theoretical expected results.

In order to further analyze the government policy intervention tendency on the real estate prices, the variance estimation and decomposition results are shown in table 3. If $\sigma_{w}^{2}$ play a dominant role in the real estate prices deviation, it shows that monetary easing policy is the main choice of the government intervention, and the intervention is conducive to the promotion of real estate prices; On the contrary, If $\sigma_{u}^{2}$ play a dominant role in the real estate prices deviation, it shows that the government has a tendency to lower the prices.

Table 3. The effect of government intervention

\begin{tabular}{|c|c|c|c|c|c|c|c|}
\hline & & & sig & & & Measure & icient \\
\hline The tendency g & nment & ention & & $\sigma$ & & 0.0491 & \\
\hline & & & & $\sigma$ & & 0.1696 & \\
\hline & & & & o & & 0.0830 & \\
\hline variance & & & & $\sigma_{v}^{2}+\sigma$ & & 0.0381 & \\
\hline decomposition & & & & $\left.\sigma_{w}^{2}\right) /(\sigma$ & $\left.+\sigma_{w}^{2}\right)$ & 0.8192 & \\
\hline & & & & $\sigma_{u}^{2} /\left(\sigma_{u}^{2}\right.$ & & 0.0774 & \\
\hline & & & & $\sigma_{w}^{2} /\left(\sigma_{u}^{2}\right.$ & & 0.9226 & \\
\hline $\begin{array}{l}\text { Seen from the } \\
\text { double effect } \\
\text { the negative } \\
\text { formation, the } \\
\text { prices to obtain }\end{array}$ & $\begin{array}{l}3 \text {, the } \\
\text { vernme } \\
\text { s accou } \\
\text { ole effe } \\
\text { revenue }\end{array}$ & $\begin{array}{l}\text { ariance o } \\
\text { icy interv } \\
\text { only } 7.7 \\
\text { the gover } \\
\text { notivatio }\end{array}$ & $\begin{array}{l}\text { ependen } \\
\text {. And in } \\
\text { Chese re } \\
\text { interve } \\
\text { wer the } 1\end{array}$ & $\begin{array}{l}\text { able is } 0 \\
\text { e two ef } \\
\text { indicate } \\
\text { do exist } \\
\text { is weak }\end{array}$ & $\begin{array}{l}\text { f which } \\
\text { the positi } \\
\text { the gove }\end{array}$ & $\begin{array}{l}92 \text { perce } \\
\text { effects ac } \\
\text { ss of the } \\
\text { nent is } m\end{array}$ & $\begin{array}{l}\text { aused by the } \\
\text { for } 92.26 \% \text {, } \\
\text { estate prices } \\
\text { cely to raise }\end{array}$ \\
\hline Table 4. Surplu & racted & 1 effect & & & & & \\
\hline & Mean & Std & MAX & MIN & $\mathrm{P} 25$ & P50 & P75 \\
\hline$\sigma_{u}^{2}$ & 0.047 & 0.0176 & 0.165 & 0.036 & 0.037 & 0.040 & 0.048 \\
\hline$\sigma_{w}^{2}$ & 0.144 & 0.1161 & 0.628 & 0.037 & 0.068 & 0.105 & 0.180 \\
\hline Net surplus & 0.097 & 0.1248 & 0.128 & -0.591 & 0.019 & 0.065 & 0.143 \\
\hline
\end{tabular}

P25, P50, P75, represents the 25,50,75 Quantile

In order to further evaluate the effectiveness of government policy interventions, this paper estimated the unilateral effects and the net effect of government intervention. The estimation results are shown in Table 4. House prices appreciation is significantly greater than that of depreciation by the government intervention. The level of the real estate prices was significantly overestimated, and the government intervention makes the average real estate prices are $9.7 \%$ overvalued. In other words, When buyers want to get a house 10,000 yuan per square meter on the fair market, they need to spend 10,970 yuan. According to statistical results from 3/4 quantile, the net effect of government intervention makes the real estate prices of $1 / 4$ areas be $14.3 \%$ overvalued, and from $1 / 4$ quantile, the net effect make the real estate prices of other $1 / 4$ areas be $1.9 \%$ overvalued. The impacts of regional government intervention polices on the real estate prices are different.

Considering the regional differences in the impacts of government intervention on the real estate prices, this paper compared the different effects of the government policy intervention in the east, middle and west. The detailed results are shown in table 5.We find that government intervention makes the strongest effect for the real estate prices in eastern China. And the net effect of the east is far more than the sum of the middle and west, The real estate prices is $23.4 \%$ overvalued in a quarter of the eastern region, and it is $13.9 \%$ overvalued in a half of the eastern region. The phenomenon of overvalued is serious, and the degree of deviation from the equilibrium prices is too large, which caused the huge pressure for buyers; The real estate prices in the central part of China are the weakest overvalued, and the average net effect is $4.9 \%$.The real estate prices is $8.7 \%$ overvalued in a quarter, and it is $0.4 \%$ undervalued 
in other quarter. Compared to the central part of China, the overvalued of western China at every quantile is slightly higher. This is because that the western plan are carried out in recent years, economic growth in western is relatively larger.

Table 5. region characteristic of dual effect

\begin{tabular}{lllll}
\hline region & Mean & & & \\
& Total & P25 & P50 & P75 \\
\hline East & 0.172 & 0.054 & 0.139 & 0.234 \\
Middle & 0.049 & -0.004 & 0.040 & 0.087 \\
West & 0.060 & 0.019 & 0.047 & 0.110 \\
\hline
\end{tabular}

P25, P50, P75, represents the 25,50,75 Quantile

The real estate prices is closely related to the national economy and people's livelihood. On the one hand, it reflects a country's economic level to a certain extent, on the other hand, as household necessities, the prices of the real estate is related to a country's residents living standards and living condition. Especially in recent years, it is controversial on Chinese housing prices. In order to complete the regulation of the real estate industry, the Chinese government issues a series of intervention policies to stabilize the real estate prices and develop the real estate economy .It is worthy to explore the impact of interventions policies on the real estate prices.so this paper lists the annual distribution characteristics of the policy intervention effects from 2008 to 2013 in table 6.

Table 6. Yearly characteristic of dual effect

\begin{tabular}{llllllll}
\hline Year & Mean & & & & & \\
& Total & P25 & P50 & P75 & East & Middle & West \\
\hline 2008 & 0.091 & 0.009 & 0.064 & 0.143 & 0.164 & 0.021 & 0.070 \\
2009 & 0.141 & 0.059 & 0.128 & 0.181 & 0.232 & 0.076 & 0.101 \\
2010 & 0.128 & 0.043 & 0.068 & 0.167 & 0.220 & 0.067 & 0.083 \\
2011 & 0.102 & 0.017 & 0.069 & 0.172 & 0.173 & 0.062 & 0.063 \\
2012 & 0.069 & 0.001 & 0.040 & 0.118 & 0.127 & 0.039 & 0.036 \\
2013 & 0.052 & -0.008 & 0.028 & 0.076 & 0.114 & 0.027 & 0.011 \\
\hline
\end{tabular}

P25, P50, P75, represents the 25,50,75 Quantile

As can be seen from Table 6, the means of the net effect is $9.1 \%$ in 2008, and it rise up to $14.1 \%$ in 2009 .During 2009 2013, the means had shown a downward tendency and dropped to 5.2\% in 2013. Every quantile shows the same trend, which means, although the government has inclined to improve prices in the past few years. But the power is weaker and weaker and the government intends to take measures to maintain prices stability. In 2009, the power of enhancing prices from government intervention reaches the maximum, and it is significantly higher than other years. When confronted with the global financial crisis. China is less affected by the financial crisis and the GDP growth rate is still strong. This is not unrelated for the government to grab the profit in the real estate industry. The trend of the net effect in the eastern, middle and western China is consistent with that of the overall. Figure 1 shows the trend of the net effect.

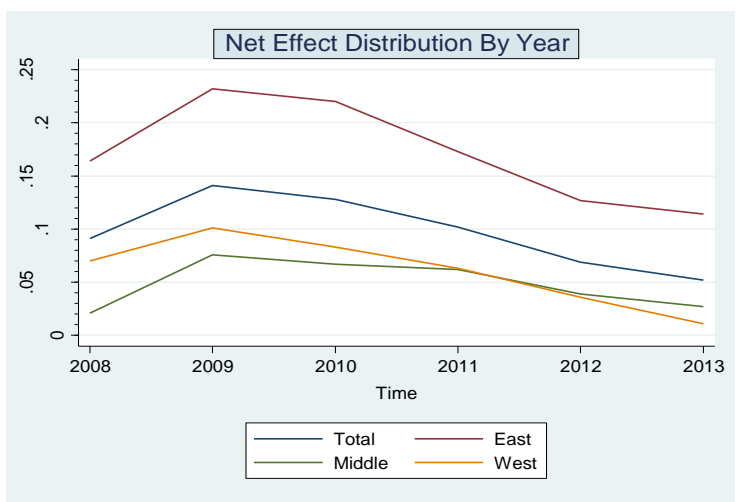

Figure 1. Net Effect Distribution By Year 
Figure 2-4 presents the distribution characteristics of the appreciation tendency, depreciation tendency and the net surplus intuitively, which caused by the government intervention policies on the real estate prices. The figure 2 and figure 3 shows that both the distribution of appreciation and depreciation tendency have the characteristics of right-trailing, which means that only in a few regions, the appreciation and depreciation tendency of government intervention is in absolutely powerful position. Seen from the distribution of the net surplus in figure 3 , the net surplus of only about $15 \%$ regions is less than zero, which means that the local government tended to stabilize people's livelihood, and took more measures to curb the rapid appreciation of the housing prices. At the same time, it also means that people were forced to accept the unreasonable prices in $85 \%$ regions. Overall, our analysis shows that the Chinese government is more inclined to take intervention measures to increase the prices in order to achieve economic development.

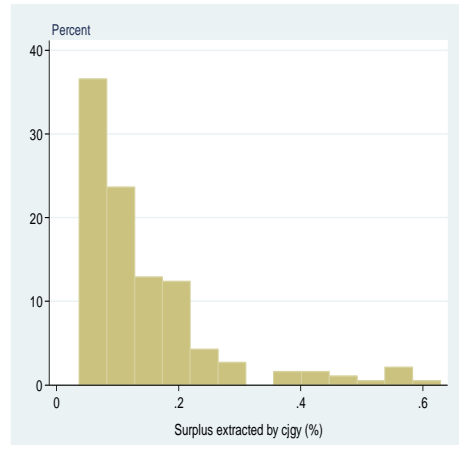

Figure 2. Positive surplus

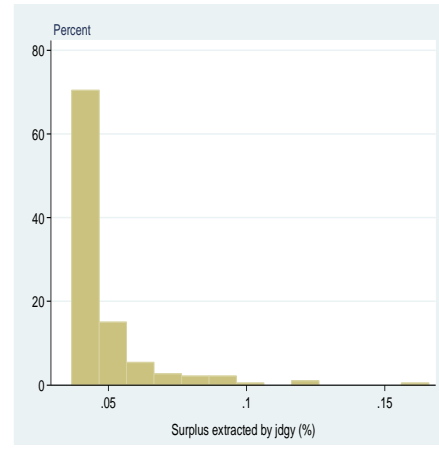

Figure 3. Negative surplus

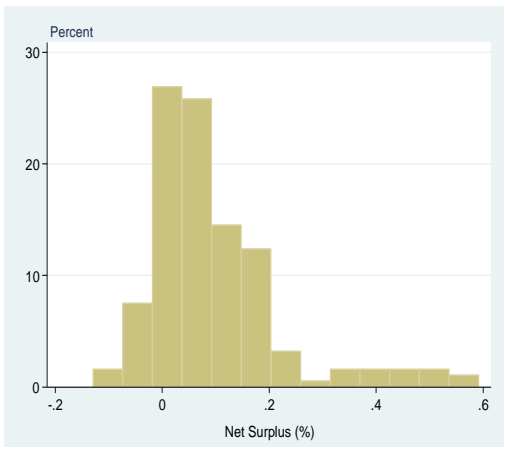

Figure 4. Net Surplus

\section{Conclusions and Suggestions}

Based on the dual effect of the government intervention on the real estate prices, this paper makes an empirical study on the impact of government intervention and draws the conclusions as follows:

Among the explained variables, the unexplained part account for $81.92 \%$ because of the dual tendency of government intervention and the comprehensive effect coefficient is 0.1205 , finally forming a higher real estate prices compared with the basis prices.

The government does significantly promote the real estate prices appreciation. The government has a tendency of $92.26 \%$ to rise real estate prices up in order to promote the economic development. On the contrary, they only has a tendency of $7.74 \%$ to push the prices down.

The government intervention on prices has presented regional characteristics significantly. The house prices is overvalued nearly $20 \%$ in the eastern China. In the central part of China, the degree is the weakest.

Although the housing prices has been overvalued in 2008-2013 under the government intervention, but the net surplus index keep decreasing constantly, which showed that the Chinese government is taking effective intervention policy to make the prices stability.

The analysis shows that over the past ten years, the Chinese government didn't introduced the corresponding intervention policy to maintain the real estate prices stable. It's not reasonable to make the GDP growth rate as a standard of bureaucratic assessment and "Land of financial" is worthy of reflection, at the same time, the fiscal decentralization system in China still need further development. According to the above problems the suggestions are as follows: (1) Improve the financial regulation system and standardize the local government land financial behavior, increase the proportion of the local government in fiscal revenue;(2)Change the achievements appraisal system based on GDP growth, reduce the adverse impact on real estate prices from local government;(3)Speed up process of the marketization of real estate and make market regulation replace the government regulation. Duo to the difficulty of defining the factors of prices, so the estimation this paper also have deviation. I will explore ways to accurately measure the degree of government intervention on property prices in future studies.

\section{References}

Amy Rehder Harris, William N. Evans \& Robert M. Schwab. (2001). Education Spending in an Aging America. Journal of Public Economics, 81(3), 449-472. http://dx.doi.org/10.1016/S0047-2727(00)00133-X

Chamon, Marcos D. \& Eswar S. Prasad. (2010). Why Are Saving Rate of Urban Households in China Rising?. 
American Economic Journal: Macroeconomics, 2(1), 93-130. http://dx.doi.org/10.1257/mac.2.1.93

Du, Hongyan, Yongkai Ma, \& Yunbi An. (2011). The Impact of Land Policy on the Relation between Housing and Land Prices; Evidence from China. The Quarterly Review of Economics and Finance, 51(1), 19-27. http://dx.doi.org/10.1016/j.qref.2010.09.004

Hongyou Lu, Guangping Yuan, Sixia Chen \& Shengfeng Chen. (2011). "Competition impulse" or "upset?" Evidence from cities. Comparative Economic \& Social Systems, (1), 88-98.

Ke Guo Land financial dependence, the financial gap and prices-Based on Provincial Panel Data. Economic Review, (2), 69-75.

Kim, E., \& J. Ju. (2003). Growth and Distributional Impacts of Urban Housing Supply: An Application of Urban Land Use and ACGE Model for Seoul. Review of Urban and Regional Development Studies, 15(1), 66-81. http://dx.doi.org/10.1111/1467-940X.00065

Kumbhakar, S. C., \& C. F. Parmeter. (2009). The Effects of Bargaining on Market Outcomes: Evidence from Buyer and Seller Specific Estimates. Journal Productivity Analysis, 31(1), 1-14. http://dx.doi.org/10.1007/s11123-008-0117-3

Lifeng Chen, Hongzhong Fan. (2014). Price fluctuations, monetary policy and China Social Welfare Loss. Chinese Journal of Management Science, (5), 42-50.

Paulo, M. B. B., \& A.M.Pereira. Housing and Endogenous Long-term Growth. Journal of Urban Economics, 51(2), 246-271.

Pengfei Yuan \& Lei Feng. (2014). Economic growth, income distribution and wealth divide. Economic Research, (9), 77-80.

Pengfei Yuan \& Weixian Wei. (2012). Research on General Equilibrium in real estate prices fluctuations. Management Science, (3), 30-43.

Shi Li, Zhong Wei \& Sai Ding. (2005). Chinese residents unequal wealth distribution and its cause analysis. Economic Research, (6), 4-15.

Song, Zheng Michael \& Dennis T. Yang. (2010). Life Cycle Earnings and the Household Saving Puzzle in a Fast-Growing Economy, ESWC 2010 Working Paper.

Songtao Wang. (2011). The principles and Evaluation of Chinese government intervention in the housing market. Statistical Research, (1), 27-35.

Xianhang Qian, Tingqiu Cao \& Weian Li. (2011). Promotion pressure, term of office and the loan behavior of city commercial banks. Economic Research, (12), 72-85.

Yanbin Chen, ZheSheng Qiu. (2011). High prices affect household savings rate and property inequality. Economic Research, (10), 25-38.

Yingzi Zhu \& Dan Xu. (2013). Pressure of Officials promoted, financial market and housing prices growth. Financial Research, (1), 65-78

Yonggang Li \& Xiang Li. (2012). Fiscal Decentralization, Local Government Competition and Price Fluctuation: An Empirical Study of China 35 cities. Soft Science, (1), 42-50.

YunQi Fan, Ge Wu. (2013). The real estate price, land prices and public spending capitalization - Analysis Based on Dynamic Panel Data of Provinces. Contemporary Finance \& Economics, (8), 34-41.

Yunwen Liang, Zhen Huo \& Kai Liu. (2010). Empirical Study of Chinese Urban and Rural Residents wealth distribution. Economic Research, (10), 33-47.

Zhuangxiong Yu \& jianhao Lin. (2010). Who pushed up prices? Developers, home buyers or government. Economist, (5), 30-38. 